\title{
28 Research Square \\ Changes in "Natural Antibiotic" Metabolite Composition During Tetraploid Wheat Domestication
}

\author{
Yuval Ben-Abu ( $\sim$ yuvalb@sapir.ac.il ) \\ Sapir College \\ Mark Itsko \\ Centers for Disease Control and Prevention
}

\section{Research Article}

Keywords: durum, emmer, metabolomics, plant defense mechanisms, wheat domestication

Posted Date: June 29th, 2021

DOl: https://doi.org/10.21203/rs.3.rs-640259/v1

License: (c) (1) This work is licensed under a Creative Commons Attribution 4.0 International License.

Read Full License 


\section{Abstract}

Plants defend themselves by producing toxins and deterrent metabolites. However, it is unclear how the composition and abundance of these natural pesticides have changed over the course of crop-plant domestication. To address this uncertainty, we characterized differences in secondary metabolites, particularly Benzoxazinoids and its derivates, among four lines of tetraploid wheat: wild emmer wheat (WEW), the direct progenitor of modern wheat; non-fragile domesticated emmer wheat (DEW), which was first domesticated about 11,000 years ago; the subsequently developed non-fragile and free-threshing durum landraces (LD); and modern durum (MD) varieties. Mass spectrometry analyses showed that the metabolome of the embryo of the mature kernel was more complex than that of the endosperm. Clear differences were observed among the metabolic profiles of WEW, DEW, and durum (LD + MD); the metabolic profiles of the two durum lines (LD and MD) were similar. Our results indicated that underappreciated classes of metabolites involved in plant defense mechanisms became significantly more abundant during wheat domestication, while other defensive metabolites decreased or were lost. It may be that the use of industrial pesticides has led to the loss of these endogenous defense metabolites. The re-expression of such "lost" metabolites in modern wheat might help to improve crop resistance, while reducing dependence on harmful industrial pesticides. In addition, we detected alterations in antioxidant composition among wheat lines, as well as increases in levels of plant hormones and antibiotic substances in the more modern lines as compared to the more primitive lines. Here, we show how DIMBOA and its derivates change during wheat domestication, and how this change may effect on the domestication of three taxonomic subspecies of tetraploid wheat (Triticum turgidum).

\section{Introduction}

Plants such as wheat (Triticum aestivum), rye (Secale cereale), and maize (Zea mays) defend themselves against bacteria, fungi, insects, or herbivores by producing toxins and deterrent metabolites such as benzoxazinones (Bxs), which are cyclic hydroxamic acids derived from indole [1] [2]. The hydroxamic acids are a family of secondary metabolites of cereals that were discovered over four decades ago in a relative of rye (Fig. 1,). Benzoxazinones are important secondary metabolites in gramineous plants and are one of the most investigated hydroxamic acids in the family Poaceae [1] [2] [3] [4] [5] [6] [7]. Benzoxazinones are natural antibiotics and also play a major role in plant defense against fungi [8] [9] [6], insects [10], and weeds [11]. The most abundant benzoxazinones are 2,4-dihydroxy-1,4-benzoxazin-3-one (DI-BOA) and its 7-methoxy analog (DIMBOA), which are constitutively present in the vacuole as glucosides (DIBOA-GIC and DIMBOA-GIC) $[12,6][13]$. Bx-glucosides are particularly important for plant defense during the juvenile stage [15].

Benzoxazinone composition and abundance change throughout plant life cycle. For example, Bxglucoside abundance is greatest soon after germination, decreasing thereafter to low levels [15]. Relative benzoxazinone abundance has also been shown to vary among plant crops (e.g., maize and wheat [21]), tissues (e.g., shoots and leaves [6]), growth habitats (e.g., arid and humid [6]), and even soil type (e.g., dry 
and wet [22]). In addition, dramatic differences in benzoxazinone content have been identified in microscale evolutionary contexts [22].

Using three taxonomic subspecies of tetraploid wheat (Triticum turgidum), we aimed to clarify how benzoxazinones were affected by plant domestication and how this change may effect on the what domestication. Tetraploid wheat, specifically wild emmer wheat (WEW; Triticum turgidum ssp.

dicoccoides,), was first domesticated about 11,000 years ago (Fig. 2) [16]. Although domesticated emmer wheat (DEW; T. turgidum ssp. dicoccum, genome BBAA, $4 x, 2 n=28$ ) was widely cultivated for several millennia, today it exists only as a relatively minor crop, having been replaced, mostly during the Roman period, by durum wheat ( $T$. turgidum ssp. durum, genome BBAA, $4 x, 2 n=28$ ), which is non-fragile and free-threshing [16] [17]. Domesticated durum varieties can be divided into ancient durum landraces (LD), locally adapted varieties that were selected by farmers and grown using low input farming practices [18], and modern durum (MD) varieties, including both dwarf and semi-dwarf lines, which were developed by plant breeders and which are grown on modern farms [CITE]. These four wheat lines represent both primary domestication (WEW to DEW) and secondary domestication (DEW to LD/WD) [24]. The durum LD and $\mathrm{MD}$ lines differ both genetically and phenotypically; we considered these lines separately in order to capture changes that occurred during the green revolution, when traditional landraces transitioned to modern varieties [24]. Hexaploid bread wheat (Triticum aestivum ssp. aestivum, genome BBAADD, 6x, 2n $=42$ ) was developed in the fertile crescent $\sim 9,000$ years ago by hybridizing tetraploid wheat (genome BBAA) with a diploid grass, Aegilops tauschii (genome DD, $2 x, 2 n=14$ ), followed by whole-genome doubling [19] [20]. Bread wheat spread from the fertile crescent to many different environments and is at present the most widely grown wheat crop [20].

In this study, we focused on domestication-associated changes in the composition and abundance of benzoxazinone and its derivates in the four lines of tetraploid wheat. Using mass spectrometry (MS), we found that the metabolome of the embryo of the mature kernel was much more complex than that of the endosperm. We then examined how domestication affected metabolite profiles by comparing modern wheat (MD) to its progenitors. To specifically investigate changes in the relative abundances of benzoxazinone and its derivates during wheat domestication, we performed an MS-coupled metabolomic analysis of the kernel embryo and endosperm to separate benzoxazinone compounds and their derivates. Our analyses revealed dramatic changes in benzoxazinone composition over the course of wheat domestication, as evidenced by distinct separations among WEW, DEW, and durum wheat; benzoxazinone profiles were similar between LD and MD. This remarkable separation among WEW, DEW, and durum highlighted the effects of domestication on benzoxazinone components. It may be that the use of industrial pesticides, climate change, or shifts in growth habitat have led to alterations in the expression patterns of these endogenous benzoxazinones. Such "lost" benzoxazinones might be valuable for improving crop resistance, while minimizing dependence on harmful industrial pesticides. Both biotic stress (e.g., pathogens) and abiotic stress (e.g., lack of nutrients, extreme temperatures and drought) may lead to oxidative stress in plants, against which antioxidants can provide protection. Thus, our results may provide a reference for the identification of optimal breeding strains with predomestication benzoxazinone profiles or of novel genes encoding for certain benzoxazinones "lost" 
during domestication, the incorporation of which may improve wheat nutritional value or pest resistance. our hypothesis that metabolite composition and expression underwent substantial changes during wheat domestication.

\section{Materials And Methods Plant material}

The study complies with local and national regulation. Nineteen accessions representing a total of four wheat lines corresponding to various stages of tetraploid wheat domestication were included in this study: five WEW accessions (T. turgidum ssp. dicoccoides), five DEW accessions, (T. turgidum ssp. dicoccum), five LD accessions (T. turgidum ssp. durum), and four MD accessions (Triticum turgidum ssp. durum; Table 1). Different wheat types were originally collected from traditional farmers from different country as described in Table 1. All plants were grown in individual $3 \mathrm{~L}$ pots in a net house under identical conditions. Three replicates of each accession were grown, and each replicate was cultivated in a separate block.

Table 1

Tetraploid wheat lines used in this study. Country of origin for each line is shown in parentheses.

\begin{tabular}{|c|c|c|c|}
\hline $\begin{array}{l}\text { Wild Emmer wheat } \\
\text { (WEW) }\end{array}$ & $\begin{array}{l}\text { Domestic Emmer } \\
\text { wheat (DEW) }\end{array}$ & $\begin{array}{l}\text { Landraces Durum } \\
\text { (LD) }\end{array}$ & Modern Durum (MD) \\
\hline $\begin{array}{l}\text { Triticum turgidum ssp. } \\
\text { Dicoccoides }\end{array}$ & $\begin{array}{l}\text { Triticum turgidum ssp. } \\
\text { dicoccum }\end{array}$ & $\begin{array}{l}\text { Triticum turgidum } \\
\text { ssp. durum }\end{array}$ & ssp. durum \\
\hline TTD20 (Israel) & $\begin{array}{l}\text { Sub-group A: TTC1 } \\
\text { (Italy) }\end{array}$ & TTR265 (Israel) & TTR16 (USA) \\
\hline TTD32 (Turkey) & $\begin{array}{l}\text { Sub-group A: TTC2 } \\
\text { (India) }\end{array}$ & TTR2 (Israel) & TTR19 (Italy) \\
\hline TTD43 (Syria) & $\begin{array}{l}\text { Sub-group A: TTC8 } \\
\text { (India) }\end{array}$ & TTR333 (Turkey) & TTR1 (Portugal) \\
\hline TTD49 (Israel) & $\begin{array}{l}\text { Sub-group B: TTC4 } \\
\text { (Israel) }\end{array}$ & $\begin{array}{l}\text { TTR5 (Morroco and } \\
\text { Tunisia) }\end{array}$ & TTR25 (Israel) \\
\hline TTD68 (Israel) & $\begin{array}{l}\text { Sub-group B: TTC6 } \\
\text { (Spain) }\end{array}$ & TTR6 (Israel) & \\
\hline
\end{tabular}

\section{Sample preparation}

Each whole grain sample was separated into endosperm and embryo, and metabolite extraction was performed as described previously [23]. In brief, the embryo and endosperm tissues (500 $\mathrm{mg}$ each) were separately ground to a fine powder in liquid nitrogen, and $1.5 \mathrm{~mL}$ of $75 \%$ methanol with $0.1 \%$ formic acid was added. After sonication at room temperature for $15 \mathrm{~min}$, each sample was centrifuged at 10,000 $\mathrm{g}$ and filtered. The filtered samples were stored at $-20^{\circ} \mathrm{C}$ prior to analysis. The metabolites in the extractable 
fractions were further purified using column chromatography (Amberlite XAD $8 \mathrm{HP}$ ) and eluted with ethanol. Both fractions were freeze-dried and stored at $-80^{\circ} \mathrm{C}$.

\section{LC-MS metabolite analysis}

Metabolite analysis was carried out using ultra-performance liquid chromatography coupled with a photodiode detector-quadrupole and tandem time-of-flight mass spectrometry (UPLC-PDA-qTOF-MS). The system consisted of a Acquity UPLC (Waters) connected in-line to an Acquity PDA detector (Waters) and a Synapt HDMS detector (Waters). The HDMS system was operated in the standard qTOF mode, without using the ion mobility capabilities. Metabolite separation was performed using a UPLC BEH C18 column (100 $2.1 \mathrm{~mm}$ i.d., $1.7 \mu \mathrm{m}$; Waters). The mobile phase consisted of $0.1 \%$ formic acid in acetonitrile/water $(5: 95, v / v)$ (phase $A)$ and $0.1 \%$ formic acid in acetonitrile (phase $B)$. The linear gradient program was as follows: $100-72 \%$ A over $22 \mathrm{~min}, 72-60 \%$ A over $0.5 \mathrm{~min}, 60-0 \%$ A over $0.5 \mathrm{~min}$, holding at $100 \%$ B for a $1.5 \mathrm{~min}$, then returning to initial conditions $(100 \% \mathrm{~A})$ over $0.5 \mathrm{~min}$, and conditioning at $100 \% \mathrm{~A}$. The flow rate was $0.3 \mathrm{~mL} / \mathrm{min}$, and the column temperature was kept at $35^{\circ} \mathrm{C}$. The UV spectra were recorded at 210-550 nm using the Acquity PDA detector (Waters), or the UV trace was measured at $240 \mathrm{~nm}$ using the Acquity UV detector (Waters). Eluting compounds were detected using the qTOF equipped with an electrospray ionization (ESI) source. Acquisition was performed in ESI-positive and ESI-negative modes. The following settings were applied during the LC-MS runs: capillary voltage, $3.0 \mathrm{kV}$; cone voltage, $30 \mathrm{eV}$; collision energy, $3 \mathrm{eV}$ and $20 \mathrm{eV}$; and collision gas, argon. For the LCMS/MS analysis, collision energies of

20 and $35 \mathrm{eV}$ were used. The $\mathrm{m} / \mathrm{z}$ range was 50-1500 Da. The MS was calibrated using sodium formate, and leucine enkephalin was used as the lock mass. A standard mixture containing $40 \mu \mathrm{g} / \mathrm{mL}$ of each of the following compounds was used to monitor the quality of the chromatogram, to ensure the consistency of retention times across runs, and to aid in metabolite identification: L-tryptophan, Lphenylalanine, p-coumaric acid, caffeic acid, sinapic acid, benzoic acid, quercetin dehydrate, kaempferol, rutin, and trans-resveratrol (all purchased from Sigma); naringenin, chlorogenic acid hemihydrate, transcinnamic acid, and isorhamnetin (Fluka); ferulic acid (Aldrich); and tomatine (Apin chemicals). Mass Lynx v4.1 (Waters) was used to control all instruments and to calculate accurate masses.

\section{LC-MS data analysis}

The chromatograms obtained using UPLC PDA-qTOF-MS analysis were processed using Marker Lynx v4.1 (Waters) to extract and align mass signals. Metabolite identification was performed as described previously on data obtained using the ESI-negative mode [27]. In brief, accurate mass and molecular formula predictions for the putative molecules were screened against the Dictionary of Natural Products (Chapman and Hall/CRC) and the SciFinder Scholar databases (SciFinder Scholar 2007). The MS/MS fragmentation and UV-absorption of the metabolites were compared with those of candidate molecules found in databases and verified using previously published studies of similar compounds.

\section{Statistical analyses}

Statistical analyses of the datasets were performed using Microsoft Excel 365 and MATLAB 8.0 with Statistics Toolbox 8.1. P-values (FDR) $<0.05$ were considered significant. We ascribed functions to 
metabolites based on searches of KEGG and HMDB, as well as complementary internet searches. Figures were generated using MATLAB 8.0, GraphPad Prism 7.0, and Meta-Chart.

\section{Results}

\section{Domestication-associated metabolomic alterations in wheat lines}

We first compared metabolomes between the embryo and endosperm of 19 accessions, representing three wild and domesticated tetraploid wheat subspecies at various stages of domestication and from a variety of eco-geographical locations (Table 1). Across all accessions, LC-MS/MS analyses detected 4886 distinct metabolites in the embryo samples and 413 metabolites in the endosperm samples, showing that the embryo metabolome was much more complex than the endosperm metabolome. Next, we generated metabolite profiles for each accession by averaging metabolite values across replicas and normalizing the distributions. Tests of group effects identified nine unique metabolites in the embryo samples and 154 unique metabolites in the endosperm samples (data not shown), again suggesting that the embryo metabolome was far more complex than the endosperm metabolome. Heatmaps of upregulated and downregulated metabolites in the embryo and the endosperm (Fig. 3A-B) revealed global patterns of metabolomic differences among the four wheat lines as well as consistent differences within lines. The dendrogram representing hierarchical clustering of the embryo metabolome heatmap showed distinct separations among the WEW, DEW, and durum lines (Fig. 3C). Interestingly, the durum accessions were divided into two subgroups, which did not correspond to LD and MD; the DEW accessions were also divided into two subgroups (Fig. 3C).

Three-dimensional (3D) principal component analyses (PCAs), run without a wheat category-bias, also demonstrated a clear separation among the WEW, DEW, and durum accessions in both the embryo and the endosperm tissues (Fig. 3). Similar to the heatmaps, the 3D PCA models did not distinguish between the MD and LD accessions (Fig. 3). We again observed two distinct subgroups within the DEW accessions (Fig. 3). These DEW subgroups were designated A and B (Table 1). Thus, the heatmaps and the PCAs were consistent with our hypothesis that metabolite composition and expression underwent substantial changes during wheat domestication.

\section{Identification of benzaxonoise metabolites associated with wheat domestication}

To identify specific changes in benzaxonoise composition, we searched the metabolites present in the wheat kernels against an annotated database [25]. We identified nine benzaxonoise metabolites in the embryo samples and seven benzaxonoise metabolites in the endosperm samples. We then characterized the metabolites that underwent significant changes during wheat domestication based on the averaged metabolomes of each group. Because there was no clear separation between LD and MD, we considered 
durum wheat a single group. We thus compared WEW to DEW, DEW to durum, and WEW to durum, with the WEW to durum comparison effectively summarizing the domestication process (Figs. 3 and 4).

\section{Discussion}

Bacteria, insects, fungi, and herbivores are frequently exposed to plant defense metabolites, either by coming into direct contact with plants or by preying on herbivores that have accumulated plant defense molecules [26] [27] [28]. Many natural enemies of wheat or other plants avoid plant defenses by rejecting herbivores that accumulate or sequester toxins [29] [30]. The toxicity levels of plant defense metabolites such as benzoxazinones may change substantially in different environments, even within a single plant species or cultivar [6]. Although the benzoxazinone hydroxamic acids have been well investigated, the effects of domestication on these secondary metabolites and their derivatives remain unclear [14]). Indeed, previous studies of kernel metabolite composition during tetraploid wheat domestication have focused primarily on primary metabolites [25], while studies of secondary metabolites have most frequently investigated the agronomic and environmental factors impacting these compounds [31]. Therefore, to our knowledge, no previous studies have characterized domestication-associated changes in the composition of secondary metabolites, particularly benzoxazinones. Our results showed that the relative abundances of several antibiotic benzoxazinoids were altered in the wheat kernel endosperm and embryo during domestication. Indeed, we identified several metabolites not previously recovered in the wheat metabolome, nor previously associated with domestication [25] [32].

Here, clear divergences among three stages of domestication (WEW, DEW, and LD/MD) were observed in the PCAs, heatmaps, and evolutionary dendrograms. No clear separation was observed between MD and LD, possibly due to the short time since the divergence of these groups (60-70 years; [CITE]) and/or a lack of selective pressure under modern farming practices. Importantly, our comparative MS-coupled metabolomics analysis revealed that the relative abundances of benzoxazinoid metabolite derivates in the wheat kernel changed substantially during primary domestication (WEW to DEW) and secondary domestication (DEW to durum; Fig. 4). These shifts in composition and abundance may be due to climate change [44] [45], biotic stress, or other types of environmental alterations [6]. Levels of antibiotic substances were greater in different stages of wheat domestication, suggesting that some species during the wheat domestication survives and some disappear. Remarkably, DIMBOA and is derivates showed significant activity during wheat domestication, may indicate to disappearance or survives according to changes in the response to biotic stressors (e.g., fungi and other pathogens).

More metabolites and more changes in metabolite composition were identified in the kernel embryo as compared to the endosperm, this mainly that the most substances in these tissues exist in the embryo. Notably, in the embryo, we detected greater levels of secondary metabolites associated with plant defense mechanisms and the response to biotic stress (Fig. 5), including phytoalexins, jasmonic acids, benzoxazinoids, glucosinolates, and other alkaloids that act as bactericides, fungicides and insecticides in various plants (Figs. 2,3 and 4) [33] [34] [35]. Specifically, benzoxazinoids were previously shown to participate in the stress response of WEW [6]. Actually, appearance or disappearance of such of theses 
Bzx, mainly in the embryo tissue that important for the next generation, may indicate about the resistance and survival of the plant [6]. Disease resistance is an adaptive trait that strongly affects crop productivity [36]. Interestingly, some defense-related metabolites (e.g., alkaloids) were downregulated in the MD lines as compared to the LD lines (Figs. 4 and 5). The use of industrial pesticides may have led to the downregulation of these endogenous pesticides [6]. The re-expression of such "lost" metabolites in modern lines might help to improve crop resistance, while minimizing dependence on harmful industrial pesticides [37]. Indeed, crop resilience might be most usefully improved by using genetic selection or engineering to increase the release of phytochemicals that confer resistance to biotic stress.

Both biotic stressors (e.g., pathogen invasion) and abiotic stressors (e.g., nutrient deficiencies, extreme temperatures, and drought) may lead to oxidative stress in plants, against which antioxidants can provide protection [38]. Genes that induce antioxidant expression in wheat may also confer disease resistance $[39,40]$. In addition, high levels of antioxidants benefit the eventual consumers of wheat as a food source $[41,42,43]$. Our comparative metabolomics analysis revealed that antioxidants, including apigenin derivatives, flavonols, and glutathiones [38], were greater in the kernels of the domesticated wheat lines as compared to the wild wheat (i.e., WEW; Fig. 5).

Our results showed that benzoxazinoid production was substantially altered over the course of domestication (Fig. 4). It may be that the use of benzoxazinoids and their derivates inhibited the expression of endogenous pesticides. Thus, our results may provide a reference for the identification of optimal breeding strains with pre-domestication benzoxazinone profiles or of novel genes encoding for certain benzoxazinones "lost" during domestication, the incorporation of which may improve wheat nutritional value or pest resistance.

\section{References}

1. Zhang X. Van Doan C., Arce CCM, Hu L., Gruenig S., Parisod C., Hibbard BE., Hervé MR., Nielson C. M. and Ricardo A. R, "Plant defense resistance in natural enemies of a specialist insect herbivore," Proc Natl Acad Sci USA, vol. 116, pp. 23174-23181, 2019.

2. Wittstock, J. Gershenzon U., "Constitutive plant toxins and their role in defense against herbivores and pathogens," Curr. Opin. Plant Biol. , vol. 5, p. 300-307, 2002.

3. Stahl E., Hilfiker O. and Reymond P. , "Plant-arthropod interactions: Who is the winner?," Plant J. 93, 703-728 (2018)., vol. 93, p. 703-728, 2018.

4. de Bruijn WJC, Gruppen $\mathrm{H}$, \& Vincken JP, "Structure and biosynthesis of benzoxazinoids: Plant defence metabolites with potential as antimicrobial scaffolds," Phytochemistry, pp. 155:233-243., 2018.

5. Arbona V \& Gomez-Cadenas A, "Metabolomics of Disease Resistance in Crops. Curr Issues Mol Biol 19:13-30.," Curr Issues Mol Biol, pp. 19:13-30., 2016.

6. Ben-Abu Y, Beiles A, Flom D, \& Nevo E, "Adaptive evolution of benzoxazinoids in wild emmer wheat, Triticum dicoccoides, at "Evolution Canyon", Mount Carmel, Israel," PLoS One, p. 13(2):e0190424., 
2018.

7. Frey M, Schullehner K, Dick R, Fiesselmann A, Gierl A., "Benzoxazinoid biosynthesis, a model for evolution of secondary metabolic pathways in plants," Phytochemistry, pp. 70(15-16):1645-51, 2009.

8. Zdero C, Bohlmann F, Niemeyer HM., "Isocedrene and guaiane derivatives from Pleocarphus revolutus. J Nat Prod. 1988. 51: 509-512," J Nat Prod. , vol. 51, p. 509-512, 1988.

9. Carlsen SC, Kudsk P, Laursen B, Mathiassen SK, Mortensen AG, Fomsgaard IS. , "Allelochemicals in rye (Secale cereale L.): cultivar and tissue differences in the production of benzoxazinoids and phenolic acids.," Nat Prod Commun. , vol. 4, p. 199-208, 2009.

10. Martos A, Givovich A, Niemeyer HM. , "Effect of DIMBOA, an aphid resistance factor in wheat, on the aphid predator Eriopis connexa Germar (Coleoptera: Coccinellidae).," J Chem Ecol. , vol. 18: 469479. , 1992.

11. P. FJ., "Allelopathic effect of hydroxamic acids from cereals on Avena sativa and A. Fatua Francisco.," Phytochemistry. , vol. 29: 773-776., 1990.

12. Dutartre L, Hilliou F, \& Feyereisen R, "Phylogenomics of the benzoxazinoid biosynthetic pathway of Poaceae: gene duplications and origin of the Bx cluste," BMC Evol Biol, vol. 12, p. 64, 2012.

13. Meredith A,. Wilkes DRM, Copeland L. , "Hydroxamic acids in cereal roots inhibit the growth of takeall.," Soil Biology and Biochemistry. , vol. 31: 1831-1836, 1999.

14. Macias FA, Valerin MD, Oliveros-Bastidas A, Castellano D, Simonet AM. , "Structure-activity relationships (SAR) studies of benzoxazinones, their degradation products and analogues. phytotoxicity on standard target species (STS).," J Agric Food Chem. , vol. 53: 538-548., 2005.

15. Nakagawa, E., Amano, T., Hirai, N. \& Iwamura, H. (, "Partial purification and characterisation of a 2,4,5-trichlorophenol detoxifying O-glucosyltransferase from wheat," Phytochemistry , vol. 38, p. 1349-1354.

16. Levy AA, Feldman M , "Intra-Population and Inter-Population Variations in Grain Protein Percentage in Wild Tetraploid Wheat, Triticum-Turgidum Var dicoccoides," Euphytica , pp. 42 (3):251-258, 1989.

17. Levy AA, Galili G, Feldman M , "Polymorphism and Genetic-Control of High Molecular-Weight Glutenin Subunits in Wild Tetraploid Wheat Triticum-Turgidum Var dicoccoides," Heredity, pp. 61:63$72,1988$.

18. Abu-Zaitoun S, Chandrasekhar K, Assili S, Shtaya M, Jamous R,Mallah O., "Unlocking the genetic diversity within a Middle-East anel of durum wheat landraces for adaptation to semi-arid climate.," Agronomy, vol. 8, pp. 233-245., 2018.

19. L. Avivi, “High grain protein content in wild wheat," Can J Genet Cytol, pp. 19:569-570, 1977.

20. Ozkan H, Levy AA, Feldman M., "Allopolyploidy-induced rapid genome evolution in the wheat (Aegilops-Triticum) group.," Plant Cell, vol. 8, pp. 1735-47, 2001.

21. Święcicka M, Dmochowska-Boguta M, Orczyk W, Grądzielewska A, Stochmal A, Kowalczyk M, Bolibok L, Rakoczy-Trojanowska M., "Changes in benzoxazinoid contents and the expression of the 
associated genes in rye (Secale cereale L.) due to brown rust and the inoculation procedure.," PLoS One, vol. 15(5), 2020.

22. Yang M, Zhang Y, Qi L, Mei X, Liao J, Ding X, Deng W, Fan L, He X, Vivanco JM, Li C, Zhu Y, Zhu S., "Plant-plant-microbe mechanisms involved in soil-borne disease suppression on a maize and pepper intercropping system.," PLoS One, vol. 9(12), 2014.

23. Hanhineva K1, Rogachev I, Kokko H, Mintz-Oron S, Venger I, Kärenlampi S, Aharoni A., "Non-targeted analysis of spatial metabolite composition in strawberry (Fragariaxananassa) flowers," Phytochemistry, Vols. 2463-2481, p. 69(13), 2008.

24. Haas M, Schreiber M, \& Mascher M, "Domestication and crop evolution of wheat and barley: Genes, genomics, and future directions," J Integr Plant Biol , pp. 61(3):204-225., 2019.

25. Beleggia R, et al., "Evolutionary Metabolomics Reveals Domestication-Associated Changes in Tetraploid Wheat Kernels," Mol Biol Evol , pp. 33(7):1740-1753, 2016.

26. Ugine TA., Krasnoff SB., Grebenok RJ., Behmer ST., \& Losey E. , “Prey nutrient content creates omnivores out of predators. Ecol. Lett. 22, 275-283 (2019).," Ecol. Lett. , vol. 22, p. 275-283 , 2019.

27. Coll M., Guershon M. , "Omnivory in terrestrial arthropods: Mixing plant and prey diets.," Annu. Rev. Entomol. 47, 267-297 (2002)., vol. 47, pp. 267-297, 2002.

28. Calvert WH., Hedrick LE., Brower LP, , "Mortality of the monarch butterfly (Danaus plexippus L.): Avian predation at five overwintering sites in Mexico.," Science, vol. 204, p. 847-851, 1979.

29. Skelhorn J., Rowe C. , "Avian predators taste-reject aposematic prey on the basis of their chemical defence.," Biol. Lett., Vols. 348-350, p. 2, 2006.

30. Kumar P.,, Pandit SS., Steppuhn A., Baldwin LT., " Natural history-driven, plant-mediated RNAi-based study reveals CYP6B46's role in a nicotine-mediated antipredator herbivore defense.," Proc. Natl. Acad. Sci. U.S.A., vol. 111, p. 1245-1252, 2014.

31. Matthews SB, et al. , "Metabolite profiling of a diverse collection of wheat lines using ultraperformance liquid chromatography coupled with time-of-flight mass spectrometry," PLoS One, p. 7(8):e44179., 2012.

32. Iannucci A, Fragasso M, Beleggia R, Nigro F, \& Papa R, "Evolution of the Crop Rhizosphere: Impact of Domestication on Root Exudates in Tetraploid Wheat (Triticum turgidum L.)," Front Plant Sci , vol. 8, p. 2124., 2017.

33. de Bruijn WJC, Gruppen H, \& Vincken JP, "Structure and biosynthesis of benzoxazinoids: Plant defence metabolites with potential as antimicrobial scaffolds," Phytochemistry, vol. 155, pp. 233-243, 2018.

34. Arbona V \& Gomez-Cadenas A, "Metabolomics of Disease Resistance in Crops," Curr Issues Mol Biol , vol. 19, pp. 13-30, 2016.

35. Okada K, Abe H, \& Arimura G., "Jasmonates induce both defense responses and communication in monocotyledonous and dicotyledonous plants," Plant Cell Physiol, vol. 56(1), pp. 16-27, 2015. 
36. Mondal S, Rutkoski JE, Velu G, Singh PK, Crespo-Herrera LA, Guzmán C, Bhavani S, Lan C, He X, Singh RP., "Harnessing Diversity in Wheat to Enhance Grain Yield, Climate Resilience, Disease and Insect Pest Resistance and Nutrition Through Conventional and Modern Breeding Approaches.," Front Plant Sci, vol. 7, p. 991, 2016.

37. Parween T, Jan S, Mahmooduzzafar S, Fatma T, \& Siddiqui ZH, " Selective Effect of Pesticides on Plant," Crit Rev Food Sci Nutr, vol. 56(1), pp. 160-179, 2016.

38. Gill SS \& Tuteja N, "Reactive oxygen species and antioxidant machinery in abiotic stress tolerance in crop plants," Plant Physiol Biochem, vol. 48(12), pp. 909-930., 2010.

39. Dhokane D, Karre S, Kushalappa AC, \& McCartney C, "Integrated Metabolo-Transcriptomics Reveals Fusarium Head Blight Candidate Resistance Genes in Wheat QTL-Fhb2," PLoS One, vol. 11(5), 2016.

40. Kage U, Yogendra KN, \& Kushalappa AC, "TaWRKY70 transcription factor in wheat QTL-2DL regulates downstream metabolite biosynthetic genes to resist Fusarium graminearum infection spread within spike," Sci Rep, vol. 42596., p. 7., 2017.

41. Masisi K, Beta T, \& Moghadasian MH, "Antioxidant properties of diverse cereal grains: A review on in vitro and in vivo studies," Food Chem, vol. 96, pp. 90-97, 2016.

42. Hostetler GL, Ralston RA, \& Schwartz SJ , "Flavones: Food Sources, Bioavailability, Metabolism, and Bioactivity," Adv Nutr, vol. 8(3), pp. 423-435, 2017.

43. Perez-Vizcaino F \& Fraga CG , "Research trends in flavonoids and health," Arch Biochem Biophys, vol. 646, pp. 107-112, 2018.

44. N. E., "'Evolution Canyon," a potential microscale monitor of global warming across life.," Proc Natl Acad Sci U S A. , Vols. 109(8):2960-5. , 2012.

45. Nevo E, Fu YB, Pavlicek T, Khalifa S, Tavasi M, Beiles A., "Evolution of wild cereals during 28 years of global warming in Israel.," Proc Natl Acad Sci U S A. , Vols. 109(9):3412-5., 2012.

46. H. KH, "Differences in nutritional quality between wild and domesticated forms of barley and emmer wheat," Plant Sci , pp. 256:1-4., 2017.

47. Shewry PR. and Sandra JH., "Food and Energy Security," Acta Chimica Slovaca, pp. 2(1): 115-138, 2009.

48. $\mathrm{KH}$, Hebelstrup, “Differences in nutritional quality between wild and domesticated forms of barley and emmer wheat," Plant Sci, pp. 256:1-4., 2017.

49. Maccaferri $\mathrm{M}$, et al. , " Durum wheat genome highlights past domestication signatures and future improvement targets," Nat Genet. , pp. 51(5):885-895, 2019.

50. D'Odorico, P., J. A. Carr, F. Laio, L. Ridolfi, and S. Vandoni, "Feeding humanity through global food trade," Earth's Future, pp. 2: 458-469, 2014.

51. Avni R, et al. , "Wild emmer genome architecture and diversity elucidate wheat evolution and domestication," Science, pp. 357(6346):93-97, 2017.

52. Luo MC, et al., "Genome sequence of the progenitor of the wheat D genome Aegilops tauschii," Nature, pp. 551(7681):498-502, 2017. 
53. M. Feldman, The origin of cultivated wheat. In The Wheat Book, A. Bonjean and W., Angus, 2001.

54. Salamini F, Ozkan H, Brandolini A, Schäfer-Pregl R, Martin W., "Genetics and geography of wild cereal domestication in the near east," Nat Rev Genet. , pp. 3(6):429-41, 2002.

55. Abbo S, Gopher A., "Near Eastern Plant Domestication: A History of Thought.," Trends Plant Sci. , pp. 22(6):491-511, 2017.

56. Moraes MC, Birkett MA, Gordon-Weeks R, Smart LE, Martin JL, Pye BJ, Bromilow R, Pickett JA. , "cisJasmone induces accumulation of defence compounds in wheat, Triticum aestivum," Phytochemistry, pp. 69(1):9-17, 2008.

57. Zörb C, Langenkämper G, Betsche T, Niehaus K, Barsch A., "Metabolite profiling of wheat grains (Triticum aestivum L.) from organic and conventional agriculture," J Agric Food Chem., pp. 18;54(21):8301-6., 2006.

58. Zörb C, Niehaus K, Barsch A, Betsche T, Langenkämper G., "Levels of compounds and metabolites in wheat ears and grains in organic and conventional agriculture.," J Agric Food Chem. , pp. 28;57(20):9555-62, 2009.

59. B. T. L. G. Zörb C, "Zörb C, Betsche T, Langenkämper G. Search for diagnostic proteins to prove authenticity of organic wheat grains (Triticum aestivum L.)," J Agric Food Chem., pp. 8;57(7):2932-7, 2009.

60. Hanhineva K, Rogachev I, Aura AM, Aharoni A, Poutanen K, Mykkänen H., "Qualitative characterization of benzoxazinoid derivatives in whole grain rye and wheat by LC-MS metabolite profiling," J Agric Food Chem. , pp. 59(3):921-7, 2011.

61. Brodsky L, Moussaieff A, Shahaf N, Aharoni A, Rogachev I. , "Evaluation of peak picking quality in LCMS metabolomics data.," Anal Chem. , pp. 82(22):9177-87, 2010.

62. Ling HQ, Ma B, Shi X, Liu H, Dong L, Sun H, Cao Y, Gao Q, Zheng S, Li Y, Yu Y, Du H, Qi M, Li Y, Lu H, Yu H, Cui Y, Wang N, Chen C, Wu H, Zhao Y, Zhang J, Li Y, Zhou W, Zhang B, Hu W, van Eijk MJT, Tang J, Witsenboer HMA, "Genome sequence of the progenitor of wheat A subgenome Triticum urartu," Nature, vol. 557(7705), pp. 424-428., 2018.

63. Ullah N, Yuce M, Neslihan Ozturk Gokce Z, \& Budak H , "Comparative metabolite profiling of drought stress in roots and leaves of seven Triticeae species," BMC Genomics, vol. 18(1), p. 969, 2017.

64. H. KH, "Differences in nutritional quality between wild and domesticated forms of barley and emmer wheat," Plant Sci, vol. 256, pp. 1-4, 2017.

65. Maccaferri M, Harris NS Twardziok SO, Pasam RK, Gundlach H, Spannagl M, Ormanbekova D, Lux T, Prade VM, Milner SG, Himmelbach A, Mascher M, Bagnaresi P, Faccioli P, Cozzi P, Lauria M, Lazzari B, Stella A, Manconi A, Gnocchi M, Moscatelli M, Avni R, Deek J, "Durum wheat genome highlights past domestication signatures and future improvement targets.," Nat Genet, vol. 51(5), pp. 885-895, 2019.

66. Zimin AV, Puiu D, Hall R, Kingan S, Clavijo BJ, Salzberg SL., "The first near-complete assembly of the hexaploid bread wheat genome, Triticum aestivum.," Gigascience., vol. 6(11), pp. 1-7, 2017.

67. Pont C, Leroy T, Seidel M, Tondelli A, Duchemin W, Armisen D, Lang D, Bustos-Korts D, Goué N, Balfourier F, Molnár-Láng M, Lage J, Kilian B, Özkan H, Waite D, Dyer S, Letellier T, Alaux M; Wheat 
and Barley Legacy for Breeding Improvement (WHEALBI) consort, "Tracing the ancestry of modern bread wheats.," Nat Genet, vol. 51(5), pp. 905-911, 2019.

68. Lopes MS, El-Basyoni I, Baenziger PS, Singh S, Royo C, Ozbek K, Aktas H, Ozer E, Ozdemir F, Manickavelu A, Ban T, Vikram P., "Exploiting genetic diversity from landraces in wheat breeding for adaptation to climate change.," J Exp Bot, Vols. (12):3477-86, pp. 3477-86, 2015.

69. B. RG, "Allelopathy in crop/weed interactions-an update," Pest Manag Sci, vol. 63(4), pp. 308-326, 2007.

70. Huang L, Raats D, Sela H, Klymiuk V, Lidzbarsky G, Feng L, Krugman T, Fahima T., "Evolution and Adaptation of Wild Emmer Wheat Populations to Biotic and Abiotic Stresses.," Annu Rev Phytopathol, vol. 54, pp. 279-301, 2016.

71. Ben-David R, Dinoor A, Peleg Z, \& Fahima T, "Reciprocal Hosts' Responses to Powdery Mildew Isolates Originating from Domesticated Wheats and Their Wild Progenitor," Front Plant Sci , vol. 9, p. 75, 2018.

72. Garvin DF, Stack RW, \& Hansen JM, "Quantitative trait locus mapping of increased Fusarium head blight susceptibility associated with a wild emmer wheat chromosome," Phytopathology , vol. 99(4), pp. 447-452, 2009.

73. Mou Y, Liu Y, Tian S, Guo Q, Wang C, Wen S., "Genome-Wide Identification and Characterization of the OPR Gene Family in Wheat (Triticum aestivum L.).," Int J Mol Sci., vol. 20(8), pp. 2-18, 2019.

74. Kage U, Karre S, Kushalappa AC, \& McCartney C, "Identification and characterization of a fusarium head blight resistance gene TaACT in wheat QTL-2DL," Plant Biotechnol J, vol. 15(4), pp. 447-457, 2017.

75. Kong L, Guo H, \& Sun M , “Signal transduction during wheat grain development," Planta, vol. 241(4), pp. 789-801, 2015.

76. Nadolska-Orczyk A, Rajchel IK, Orczyk W, \& Gasparis S, "Major genes determining yield-related traits in wheat and barley," Theor Appl Genet, vol. 130(6), pp. 1081-1098, 2017.

77. Li W \& Yang B, "Translational genomics of grain size regulation in wheat," Theor Appl Genet, vol. 130(9), pp. 1765-1771, 2017.

78. Qi PF, Jiang YF, Guo ZR, Chen Q, Ouellet T, Zong LJ, Wei ZZ3, Wang Y, Zhang YZ, Xu BJ, Kong L, Deng M, Wang JR, Chen GY, Jiang QT, Lan XJ, Li W, Wei YM, Zheng YL., "ranscriptional reference map of hormone responses in wheat spikes," BMC Genomics, vol. 20(1), p. 390, 2019.

79. Hill CB \& Li C, "Genetic Architecture of Flowering Phenology in Cereals and Opportunities for Crop Improvement," Front Plant Sci, vol. 7, p. 1906, 2016.

80. Jiang Y, Schmidt RH, Zhao Y, \& Reif JC, " A quantitative genetic framework highlights the role of epistatic effects for grain-yield heterosis in bread wheat," Nat Genet, vol. 49(12), pp. 1741-1746, 2017.

81. Fatiukha A, Filler N, Lupo I, Lidzbarsky G, Klymiuk V, Korol AB, Pozniak C, Fahima T, Krugman T, "Grain protein content and thousand kernel weight QTLs identified in a durum $\times$ wild emmer wheat mapping population tested in five environments," Theor Appl Genet, 2019. 
82. Ben-Abu Y., Tzfadia O., Maoz Y., Kachanovsky D.E., Melamed-Bessudo C., Feldman M., Levy A.A, “Durum wheat evolution-- a genomic analysis," Proceedings of the International Symposium on Genetics and Breeding of Durum Wheat, vol. 110, pp. 29-44, 2014.

83. Givovich A, Morse S, Cerda H, Niemeyer HM, Wratten SD. , “ Hydroxamic acid glucosides in honeydew of aphids feeding on wheat.," J Chem Ecol., vol. 18: 841-846., 1992.

84. arlsen SC, Kudsk P, Laursen B, Mathiassen SK, Mortensen AG, Fomsgaard IS. , "Allelochemicals in rye (Secale cereale L.): cultivar and tissue differences in the production of benzoxazinoids and phenolic acids.," Nat Prod Commun. , vol. 4(2): 199-208, 2009.

85. Zdero C, Bohlmann F, Niemeyer HM., "Isocedrene and guaiane derivatives from Pleocarphus revolutus.," J Nat Prod. , vol. 51: 509-512, 1988.

86. Meredith A,. Wilkes DRM, , "Copeland L. Hydroxamic acids in cereal roots inhibit the growth of takeall.," Soil Biology and Biochemistry. , vol. 31: 1831-1836, 1999.

87. P. FJ., "Allelopathic effect of hydroxamic acids from cereals on Avena sativa and A. Fatua Francisco.," Phytochemistry., vol. 29: 773-776, 1990.

88. Macias FA, Valerin MD, Oliveros-Bastidas A, Castellano D, Simonet AM. , "Structure-activity relationships (SAR) studies of benzoxazinones, their degradation products and analogues. phytotoxicity on standard target species (STS)," J Agric Food Chem. , vol. 53, pp. 538-548, 2005.

89. Givovich A, Morse S, Cerda H, Niemeyer HM, Wratten SD. , “Hydroxamic acid glucosides in honeydew of aphids feeding on wheat.," J Chem Ecol., vol. 18, p. 841-846, 1992.

90. Meredith A,. Wilkes DRM, Copeland L., " Hydroxamic acids in cereal roots inhibit the growth of takeall. Soil Biology and Biochemistry. 1999. 31: 1831-1836," Soil Biology and Biochemistry, vol. 31, p. 1831-1836, 1999.

91. Perez FJ., "Allelopathic effect of hydroxamic acids from cereals on Avena sativa and A. Fatua Francisco.," Phytochemistry. , vol. 773-776, p. 29, 1990.

92. Shavit R, Batyrshina ZS, Dotan N, Tzin V., "Cereal aphids differently affect benzoxazinoid levels in durum wheat.," PLoS One, vol. 13(12), 2018.

\section{Figures}




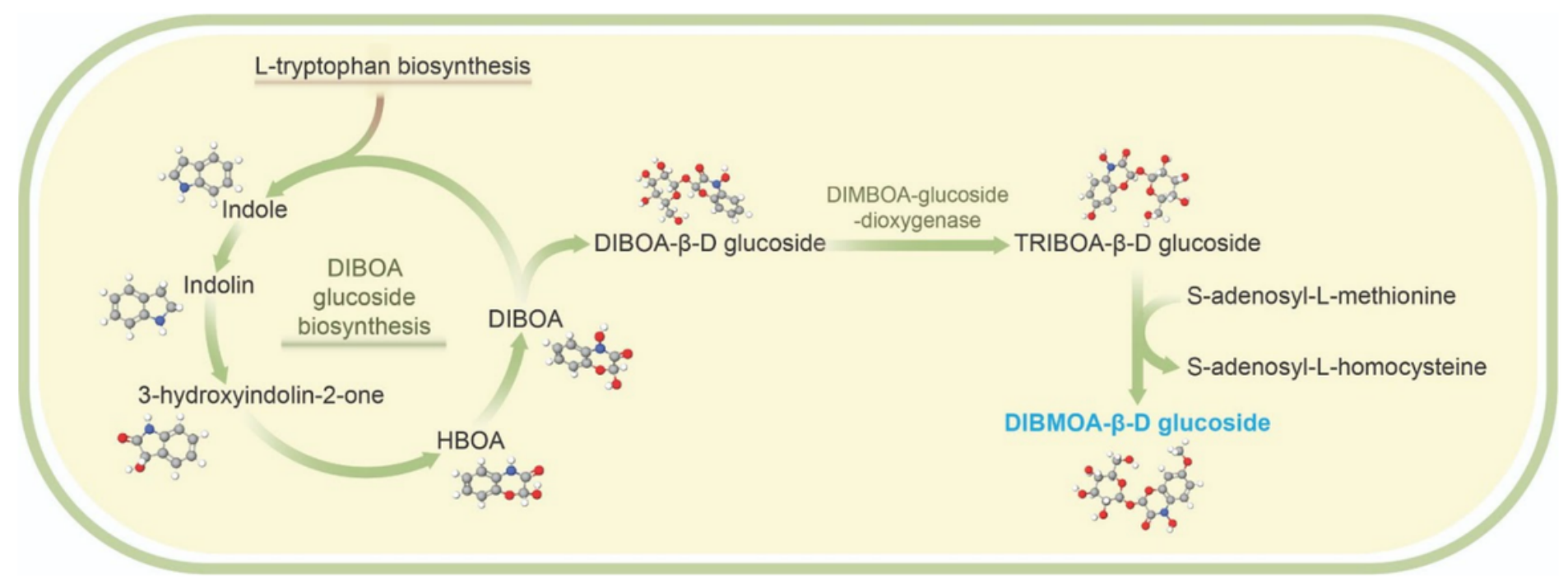

\section{Figure 1}

Schematic representation of the benzoxazinone (Bx) biosynthetic pathway, showing the enzymatic reactions catalyzed by the gene products of $\mathrm{TaBx} 1-\mathrm{TaBx} 5$ in the plastids and microsomes of tetraploid wheat.

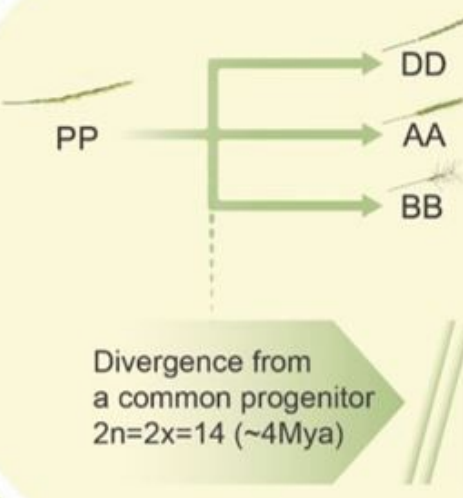

Formation of wild allotetraploid wheat $2 \mathrm{n}=4 \mathrm{x}=28(\sim 0.5 \mathrm{Mya})$

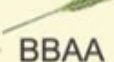

Domestication of allotetraploid wheat $2 n=4 x=28$ ( 10,500 Cal BP)
Formation of allohexaploid wheat $2 n=6 x=42$ ( 9,500 Cal BP)

Figure 2 
Evolutionary history of allotetraploid and allohexaploid wheat: Diploid wheats $(2 n=2 X=14)$, from the Tritcum-Aegilops group have diverged $\sim 4$ Mya from a diploid progenitor whose genome is indicated here as PP. Intergeneric hybridization between the diploid T. urartu (genome AA) as male and the donor of BB genome as female, (an unknown species similar to Ae. speltoides), followed by chromosome doubling, gave rise ( $0.5 \mathrm{Mya})$ to the wild allotetraploid wheat, Triticum turgidum,ssp. dicoccoides (genome BBAA, $2 n=4 x=28$ ), the direct progenitor of durum and bread wheat. Domestication of allotetraploid wheat took place $\sim 10,500$ years ago and was followed by a second round of intergeneric hybridization chromosome doubling between domesticated allotetraploid wheat and the donor of the $D$ genome, Ae. Tauschii $(2 n=2 X=14$, genome $D D)$, giving rise, $\sim 9000$ years ago, to bread wheat, an allohexaploid $(2 n=6 X=42$, genome AABBDD). 
A

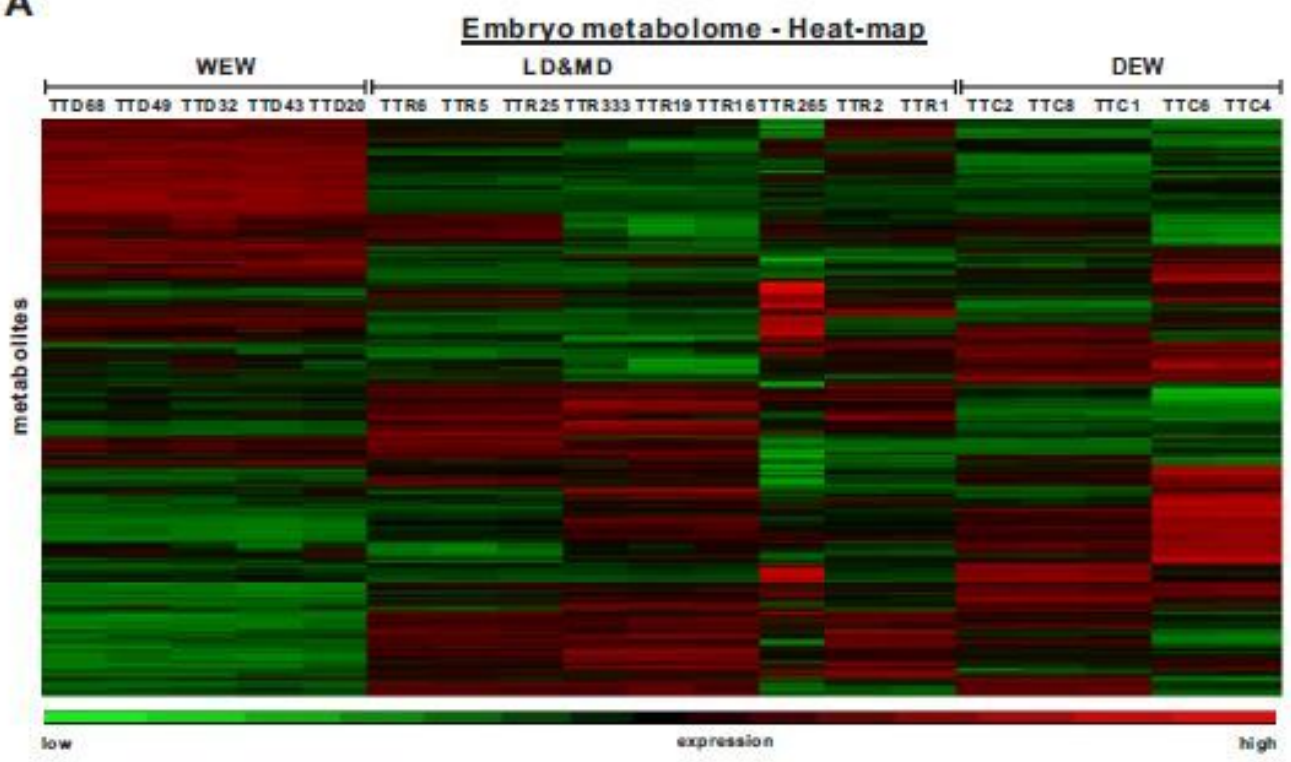

B

Endosperm metabolome - Heat-map

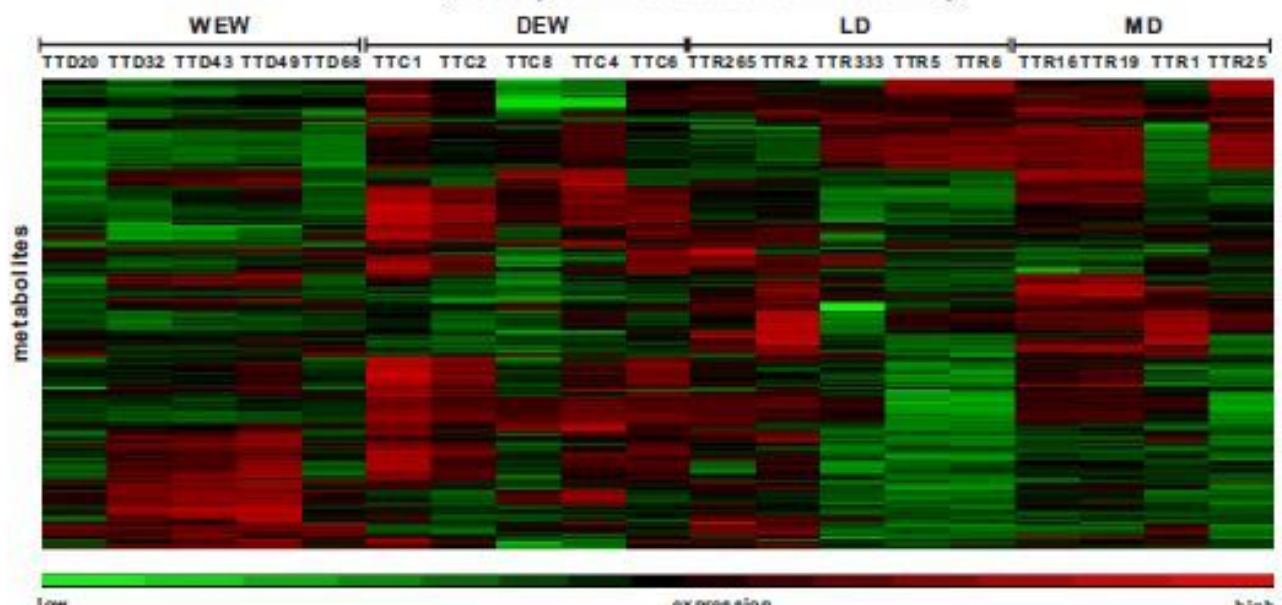

C

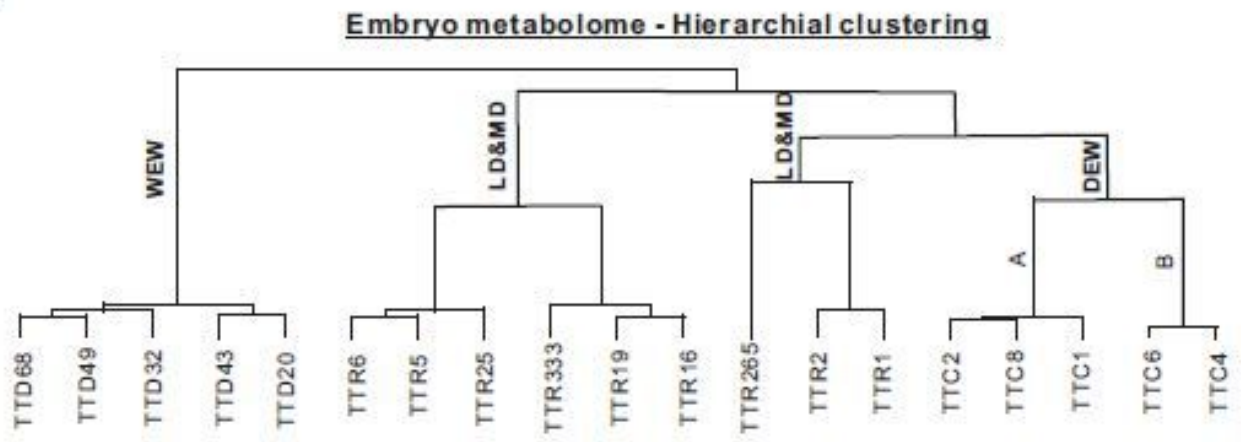

\section{Figure 3}

The embryo and endosperm metabolomes of 19 wheat accessions, representing three wild and domesticated tetraploid wheat subspecies at various stages of domestication: wild emmer wheat (WEW; T. turgidum ssp. dicoccoides), domesticated emmer wheat (DEW; T. turgidum ssp. dicoccum), durum landraces (LD; T. turgidum ssp. durum), and modern durum (MD; Triticum turgidum ssp. durum; see Table 1 for details of each accession). (A-B) Heat-maps of the (A) embryo and (B) endosperm metabolomes, 
generated based on the quantile-normalized average values of metabolites per accession. Red metabolites were upregulated, and green metabolites were downregulated. (C) Dendrogram showing relationships among the wheat embryo metabolomes based on the hierarchical clustering patterns of the heat-map shown in (A). The longer the Euclidean distance between two accessions, the greater the difference between the respective metabolomes.

A

Embryo metabolome-PCA
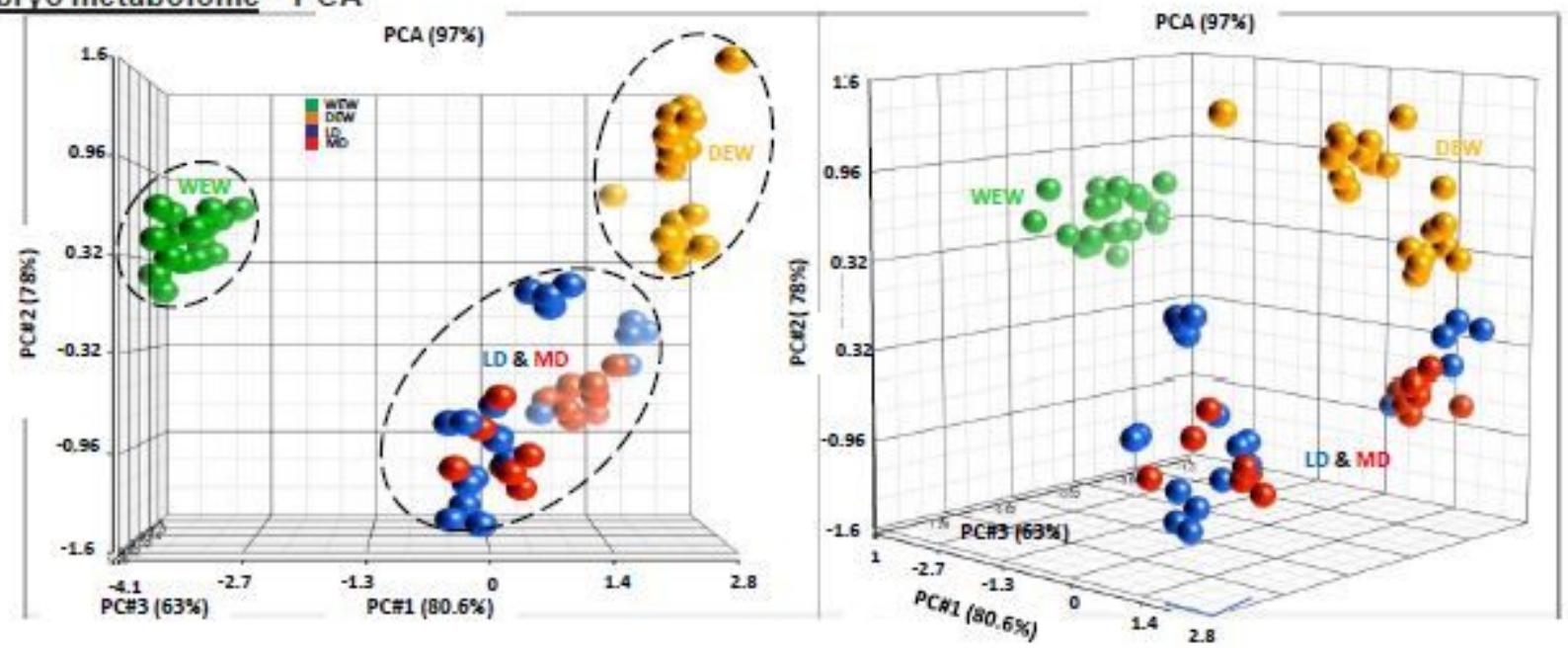

B

Endosperm metabolome-PCA
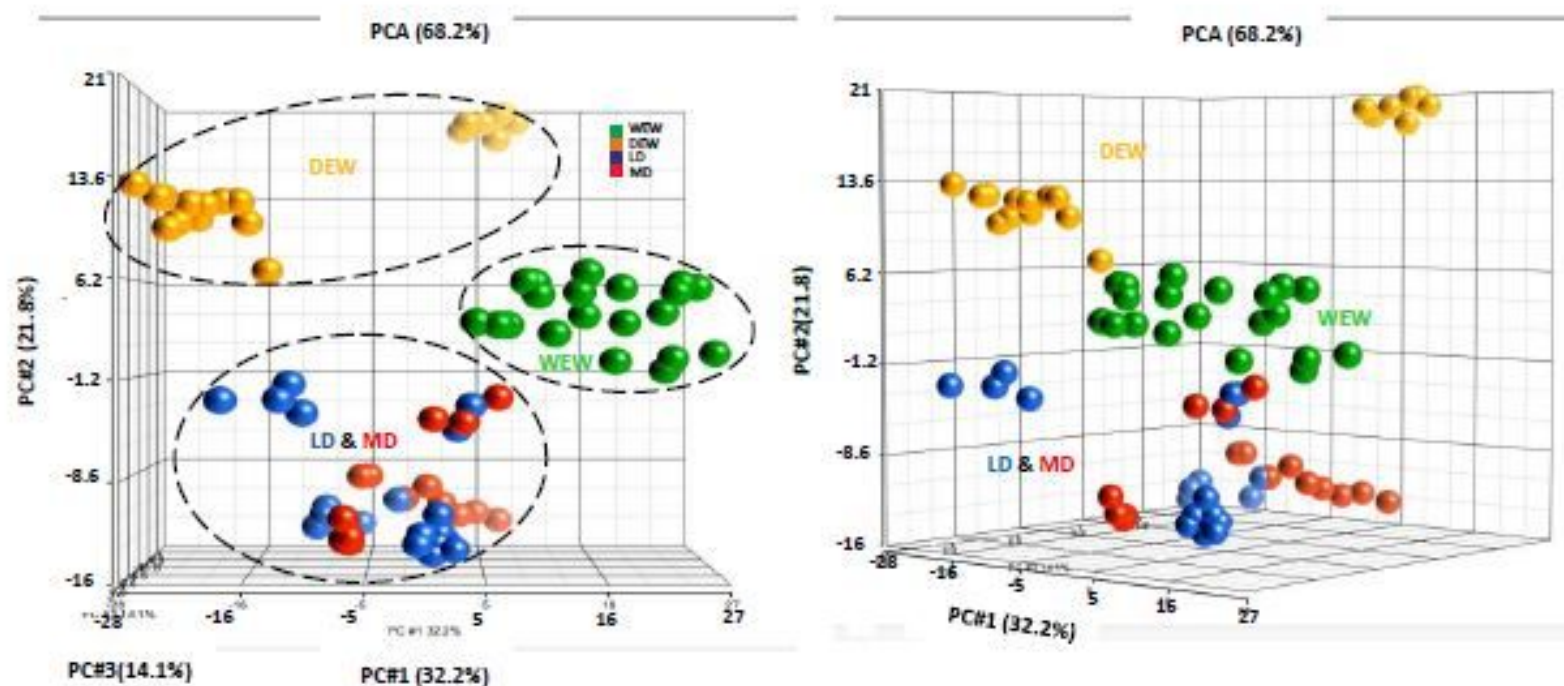

Figure 4

Three-dimensional models of principal component analyses (PCA) of the 19 wheat accessions, representing three wild and domesticated tetraploid wheat subspecies at various stages of 
domestication: wild emmer wheat (WEW; T. turgidum ssp. dicoccoides), domesticated emmer wheat (DEW; T. turgidum ssp. dicoccum), durum landraces (LD; T. turgidum ssp. durum), and modern durum (MD; Triticum turgidum ssp. durum; see Table 1 for details of each accession). Each sphere represents the quantile-normalized metabolome of one replicate accession; well-separated groups are indicated with dashed lines. (A) Two views of the PCA of the embryo metabolomes. (B) Two views of the PCA of the endosperm metabolomes.
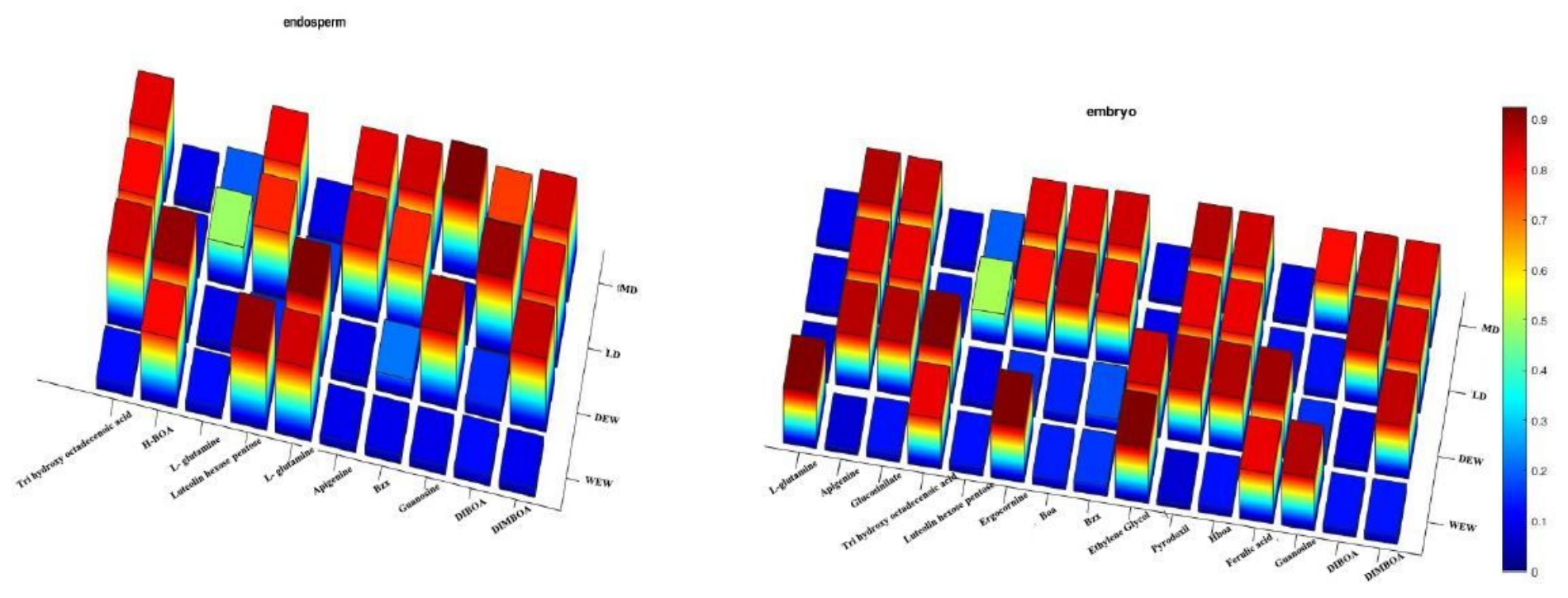

Figure 5

Changes in normalized benzoxazinone metabolites- natural antibiotic metabolites profile during tetraploid wheat domestication in the (A) endosperm and (B) embryo. 